\title{
New Magnetic Cyclone Model, Bombogenesis, Associated Supernova and Nova Effects
}

\author{
WP Sokeland* \\ Retired, Heat Transfer Expert, Spacecraft and Turbine Engines, USA \\ *Corresponding author: WP Sokeland Retired, Heat Transfer Expert, Spacecraft and Turbine Engines, USA
}

\begin{abstract}
The tropical cyclone model weathermen have blessed for at least 50 years will have to change before research in this field can progress. The old model called a cyclone, typhoon, or hurricane produces its power by absorbing heat energy from warm ocean waters. If the storm continues to exist when passing over cold waters, weathermen simply change the name to bombogenesis because it cannot be a cyclone and exist over cold waters or land. The tropical cyclone is a storm containing its own positive magnetic field with positive ions revolving at high velocities. Its magnetic field strength is stronger than Earth's magnetic field, but positive and negative magnetic anomalies of our planet cause change in direction and rapid intensification for our magnetic storm. The incoming high velocity positive particle debris streams of exploding stars affect existing cyclones by changing their velocity and direction and if the storm moves over cold water causes it to become a stronger storm without ocean heat, bombogenesis. The proof of the new model is "graveyards of ships" that coincide with a restricted areas of Earth's positive magnetic anomalies where the ships are thousands of years old and have been collected over a long period of time at a location where the magnetic storm intensifies due to the magnetic anomaly.
\end{abstract}

Keywords: Bombogenesis; Hurricane intensification; Exploding star; Augmentation

\section{Introduction}

The Typhoon Nuri 2014 becomes a Jekyll and Hyde storm for our report because it is a super typhoon over warm waters east of Japan and a few days later turns into a bombogenesis storm over cold waters in the Bering Sea $[1,2]$. Both times our Jekyll and Hyde storm intensifies, it was augmented by an incoming exploding star debris stream of positive ions. An extraordinary feature of this storm is the loop in its path in the Bearing Sea shown in (Figure 1). The change in direction of the storm's path in the Bearing Sea indicates the Earth has a negative magnetic anomaly in the Bearing Sea. The negative magnetic anomaly also reduces the strength of the storm's magnetic field and the storm reduces in velocity and may ceases to exist. The positive magnetic pole of the storm and the negative magnetic anomaly of the Earth exert a force on each other by the law of physics; unlike magnetic poles attract each other [3]. When the positive magnetic moveable storm comes close to the immoveable negative anomaly, the resulting force causes the storm to circle the area of the negative magnetic anomaly. The negative magnetic anomaly in the Bearing Sea is shown as a blue area circled in red on the right-hand side of (Figure 2) [4]. The report of Andrew's intensification shows the same loop and negative magnetic anomaly effect for Hurricane Ophelia. Every cyclone that shows a loop in its path is experiencing the effect of a negative magnetic anomaly and the path of half a loop is a repelling force keeping the hurricane away from Earth's positive magnetic anomaly. When a hurricane passes over a positive magnetic anomaly its magnetic field increases in strength and the wind speed increases providing it has not used all its positive ions and became just a column of revolving air.

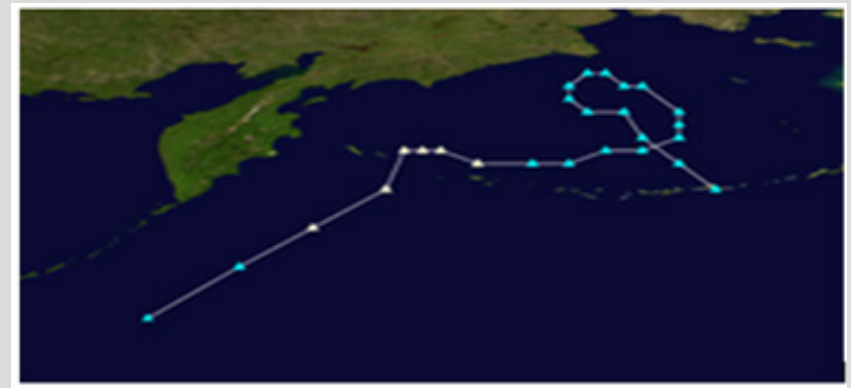

Figure 1: Bombogenesis Storm's Loop-Bearing Sea 


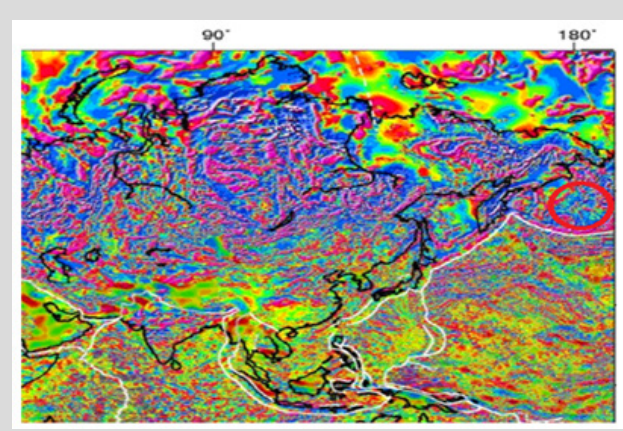

Figure 2: Bering Sea Negative Magnetic Anomaly Blue or Grey -Positive Anomaly Red

\section{Discussion}

Examples of rapid intensification, RI, for the magnetic model of a typhoon can be shown for Nuri east of Japan via exploding star WZ Sagittae incoming debris stream. Some of the terms used for an exploding star are eastern terminus, ET, deflection area, DA, and western terminus, WT. These three longitudes define the 180-degree path of the incoming debris stream or hotspot. The hotspot will exist at three locations at the calculated theoretical longitude and are called northern, southern, and central tines. The hotspot will travel from east to west and reverse directions when it encounters a terminus. It will move through the deflection area point that is always between the two termini. The hotspot may also be referred to as the storm. It has incoming positive particles that deliver energy to the atmosphere and cause lightning. The longitude locations also have a date when maximum cosmic accumulations of meteors, CAM, occur. These parameters can be calculated by knowing the right ascension of the exploding star's remnant and since the remnant does not move, the CAM dates, ET, DA, and WT are at the same locations on the Earth each year. There will be adjustments to get from the theoretical longitudinal values to the real longitudinal values due to a positive particle or meteor moving through Earth's magnetic field. The velocity of the hotspot is defined as moving one longitude degree per day. This result because the hotspot moves from ET to WT and back to ET in one year, 365 days, through 360 degrees. There is a small error that is insignificant for our purposes. The one degree per day rule, ODPDR, can be used to calculate the day and location of the hotspot for nonCAM dates. The simple equations used to calculate these variables for a remnant are shown on the first page of [5].

\section{Saiga example calculation}

The Saiga antelope experienced an unusual death rate of 22,000 in three weeks. In previous works the author incorrectly identified this phenomenon with SN1006 in 2014 when it was really the work of V603 Aquilae in 2015. The right ascension, RA, of the remnant of V603 Aquilae is $18 \mathrm{~h} 48 \mathrm{~m} 54.6366 \mathrm{~s}$ or $18.815 \mathrm{~h}$. Using the equation,

$$
\mathrm{RA}=24(\mathrm{DOY}-79) / 365
$$

calculate the eastern terminus CAM day of the year, DOY. The CAM DOY equals 365 or December 31 for the eastern terminus. By definition the CAM date for the western terminus is 182.5 days away from the ET CAM date or DOY 183 or July 2. The equation for the western terminus longitude, $\mathrm{L}$, is

$$
L=13 W+360(15-R A) / 24 .
$$

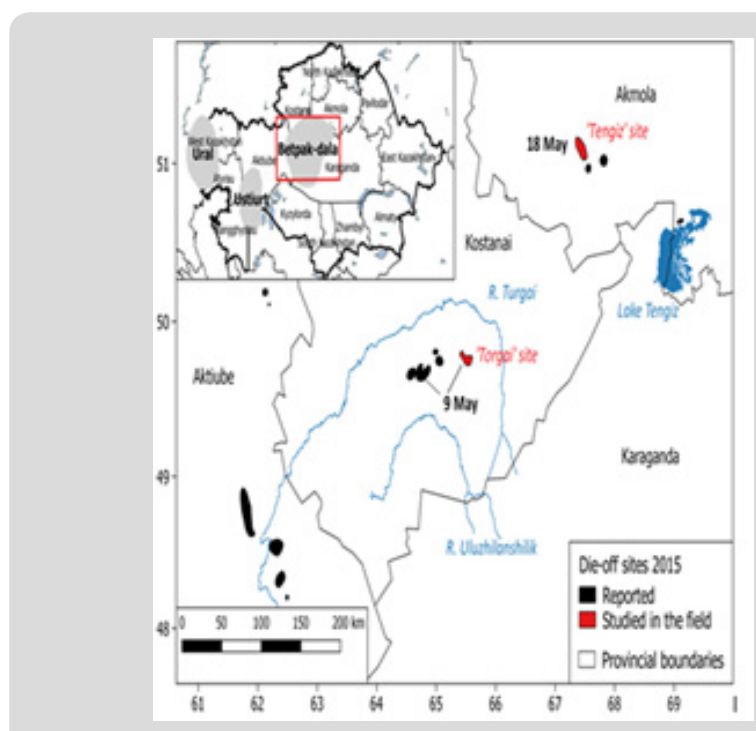

Figure 3: Saiga Die Off Locations [6].

The part of the equation to the right of the plus sign equals -57 degrees. The minus sign means the remnant RA is larger than 15 indicating the $13 \mathrm{~W}$ longitude point must be moved 57 degrees to the east or 44E is the theoretical longitude for V603 Aquilae's western terminus. The eastern terminus is 180 degrees away on the other side of the planet or $136 \mathrm{~W}$ is the theoretical longitude for V603 Aquilae's eastern terminus. The DA is 75 degrees from the eastern terminus or 149E and using the ODPDR has a CAM date of March 17. When the hotspot is returning from the western terminus the DA location will be 105 degrees from the date July 2 or DOY 288 or October 14. The calculated data are shown for V603 Aquilae in Table 1 that contains the same data for other exploding stars. To proceed with the sample problem, the maximum death rate was May 8,2015 . The central tine hotspot is moving west. Using the ODPDR March 17 to May 8 is 51 days or degrees from 149E going west gives $98 \mathrm{E}$ as the theoretical longitude location for the death of the Saiga. The theoretical location must be adjusted 30 degrees west to obtain the real longitude location for the Saiga deaths as 68E on May 8. This is close to the value of 66E shown in (Figure 3). In (Table 1) the year of impact for Nova V603 Aquilae was 2015 and the maximum strength or density of incoming particles is greatest for all points in the 180-degree path when the time being considered is near the time of impact.To complete the example problem, V603 Aquilae had an outburst or explosion in 1918 at a distance of 810 light years from Earth [7]. Using the modified equation to determine the constant for the ETA equation shown below,

$$
\text { Constant }=(0.13337-0.119)(N R D-142) /(7543-142)+
$$

Where NRD = New Remnant Distance, 810 light years, gives 0.12029 for the constant. The year of impact for the V603 Aquilae 
debris streams due to the observed outburst of 1918 is calculated by the equation,

$$
\text { ETA }=\text { Constant } \Delta \mathrm{T}_{\mathrm{L}}+\mathrm{T}_{\mathrm{L}}
$$

Where ETA= year of impact, $\Delta \mathrm{T}_{\mathrm{L}}=$ light years to remnant, $\mathrm{T}_{\mathrm{L}}=$ age of remnant or year of outburst. The ETA is 2015.

\section{Storm nuri intensification east of Japan november 2}

Notice CAM dates November 2 for debris storms of SN1006 and WZ Sagittae in (Table 1). The longitude locations for the eastern terminus, ET, and deflection area, DA, for the storms or hotspots are $167 \mathrm{E}$ and $170 \mathrm{E}$ in (Table 1) respectively. A shift of 30 degrees to the west due to the Earth's magnetic effects for the theoretical locations give $137 \mathrm{E}$ and $140 \mathrm{E}$ as the maximum density real locations for incoming exploding star positive particles on November 2 of any year. A typhoon named Nuri of the 2014 season on November 2 became a super typhoon after beginning as a solar typhoon, a typhoon produced by an explosion on our sun, on October 31 [1].
The storm increased in intensity rapidly November 2 to 4 at 133 to 135 east longitude. When considering the DA and ET longitude values in (Table 1) for SN1006 and WZ Sagittae and shifting the theoretical longitudes 30 degrees west, the real longitudes of $137 \mathrm{E}$ and $140 \mathrm{E}$ define the longitudes of maximum particle density for the two exploding star debris streams, respectively. The longitude values of the typhoon from Table 1 for exploding stars match the longitude values from the hurricane archive for storm Nuri with sufficient accuracy to state the storm has been augmented by the exploding star debris streams to wind speeds of $180 \mathrm{mph}$. It is rather interesting that the latitude of the intensification was $17.2 \mathrm{~N}$ to $17.9 \mathrm{~N}$ and the declination of WZ Sagittae is +17.75 . It should be noted that the hurricane archive data have selected the central tine of WZ Sagittae as the exploding star debris stream that produced the rapid intensification for typhoon Nuri when located east of Japan and the northern tine of SN1006 whose declination is -42 could also contribute.

Table 1: Star Data for Remnants - SNIT Theory.

\begin{tabular}{|c|c|c|c|c|}
\hline Remnant/Declination & Impact Year (Loc. Dominate Tine) & WT/ET & CAM dates & Longitude \\
\hline \multirow[t]{3}{*}{ SN 1006/ - 42} & \multirow[t]{3}{*}{ December 2011-2012 (North) } & WT & 2-May & 13W Yellow \\
\hline & & DA & Jan 16, Aug 15 & $92 \mathrm{E}$ \\
\hline & & ET & 2-Nov & $167 \mathrm{E}$ \\
\hline \multirow[t]{3}{*}{ SN $1054 /+22$} & \multirow[t]{3}{*}{2005 (South) } & WT & 12-Dec & 155W Blue \\
\hline & & DA & Mar 25, Aug 26 & $50 \mathrm{~W}$ \\
\hline & & ET & 12-Jun & $25 \mathrm{E}$ \\
\hline \multirow{3}{*}{ WZ Sagittae / +17.75 } & \multirow{3}{*}{$\begin{array}{c}\text { 1933, August 1987, 1998, March 28, } 2017 \text { (North } \\
\text { in June \& Dec) }\end{array}$} & WT & 20-Jul & 65E Red \\
\hline & & DA & April 5, Nov 2 & $170 \mathrm{E}$ \\
\hline & & ET & 20-Jan & $115 \mathrm{~W}$ \\
\hline \multirow[t]{3}{*}{ V606 Aquilae / -0.1 } & \multirow[t]{3}{*}{1989} & WT & 9-Jul & 52E White \\
\hline & & DA & Mar 24, Oct 22 & 53W \\
\hline & & ET & 8-Jan & $128 \mathrm{~W}$ \\
\hline \multirow[t]{3}{*}{ V603 Aquilae / +0.5 } & 2015 (North in January) & WT & 2-Jul & 44E Green \\
\hline & \multirow[t]{2}{*}{ (Saiga deaths) } & DA & Mar 17, Oct 14 & $149 \mathrm{E}$ \\
\hline & & ET & 31-Dec & $136 \mathrm{~W}$ \\
\hline \multirow[t]{3}{*}{ SS Cygni/ +43 } & \multirow[t]{3}{*}{ (South) } & WT & 13-Aug & 88E Orange \\
\hline & & DA & April 29, Nov 26 & $17 \mathrm{~W}$ \\
\hline & & ET & 13-Feb & $92 \mathrm{~W}$ \\
\hline \multirow[t]{3}{*}{ SN Veil Nebula/ +31 } & \multirow[t]{3}{*}{ (South) } & WT & 30-Jul & 73E Pink \\
\hline & & DA & May 15 , Oct 12 & $2 \mathrm{~W}$ \\
\hline & & ET & 30-Jan & $107 \mathrm{~W}$ \\
\hline
\end{tabular}




\begin{tabular}{|c|c|c|c|c|}
\hline \multirow[t]{3}{*}{ SU Draconis/ +67 } & \multirow[t]{3}{*}{ (South) } & WT & 14-Mar & 64W Black \& Brown \\
\hline & & DA & June 27, November 27 & 41E Black Ring \& Brown Line \\
\hline & & ET & 13-Sep & 116E Black \& Brown \\
\hline \multirow[t]{3}{*}{ CK Vulpeculae/ +27 } & \multirow[t]{3}{*}{ 1910-12 (South) } & WT & 16-Jul & 60E Grey \\
\hline & & DA & Mar 31, Oct 29 & $45 \mathrm{~W}$ \\
\hline & & ET & 15-Jan & $120 \mathrm{~W}$ \\
\hline Variation & & & Tolerance $\pm 5 \%$ & Deflection (q/M) \\
\hline Bulge & & & & Circular area \\
\hline
\end{tabular}

For those that enjoy adding momentum vectors, at the time or location where typhoon Nuri was augmented by WZ Sagittae's debris stream, Nuri was headed north and from Table 1 the debris stream of WZ Sagittae was headed east and the new direction, northeast, of the merged or augmented storm indicates the original storm's momentum was greater than the added momentum of the WZ Sagittae's debris stream as shown in (Figure 4) [1].

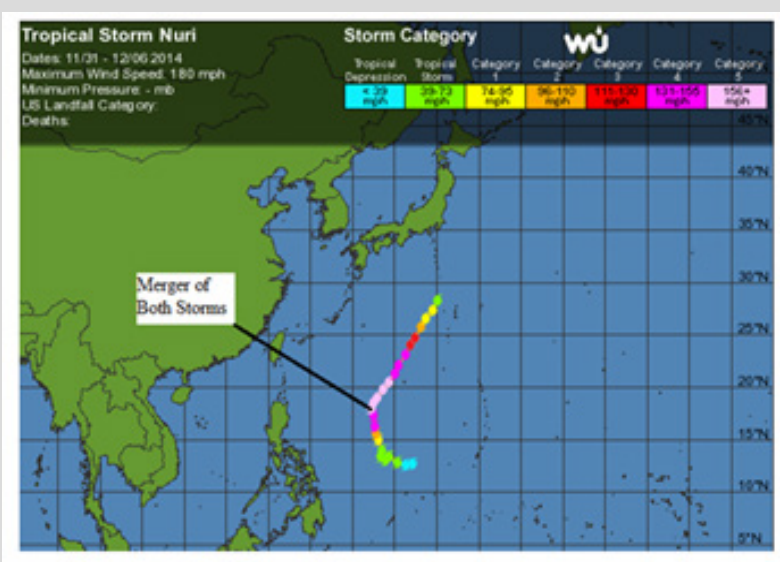

Figure 4: Typhoon Nuri East of Japan [1].

\section{Bombogenesis Storm from Typhoon Nuri November 2014}

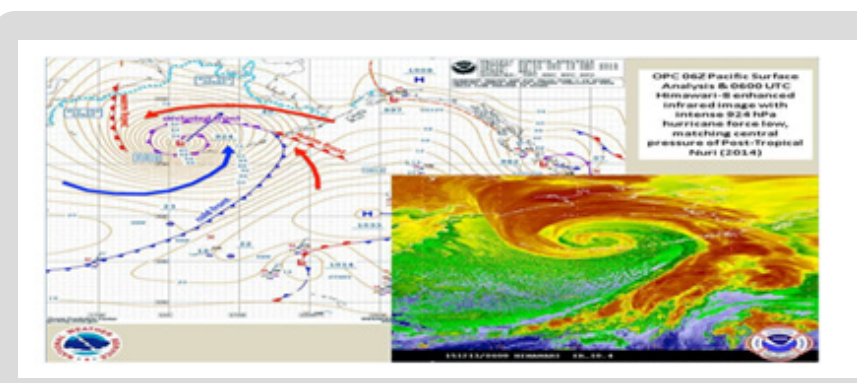

Figure 5: New Storms Record Low Pressure [8].

The Hyde part of the storm appears as a Bering Sea cyclone November 7, 2014 due to another exploding star debris stream. The longitude location and time data do not appear in Table 1, but there are other ways to show a powerful longitudinal location. The center of the storm in the Bering Sea on November 6 shown in (Figure 5) matches the $180 \mathrm{~W}$ longitude location of the outstanding hotspot shown in (Figure 6), top center. The hotspot and intensification are produced by the same incoming debris stream of an unknown exploding star and as a result appear on the same longitude at the same time.

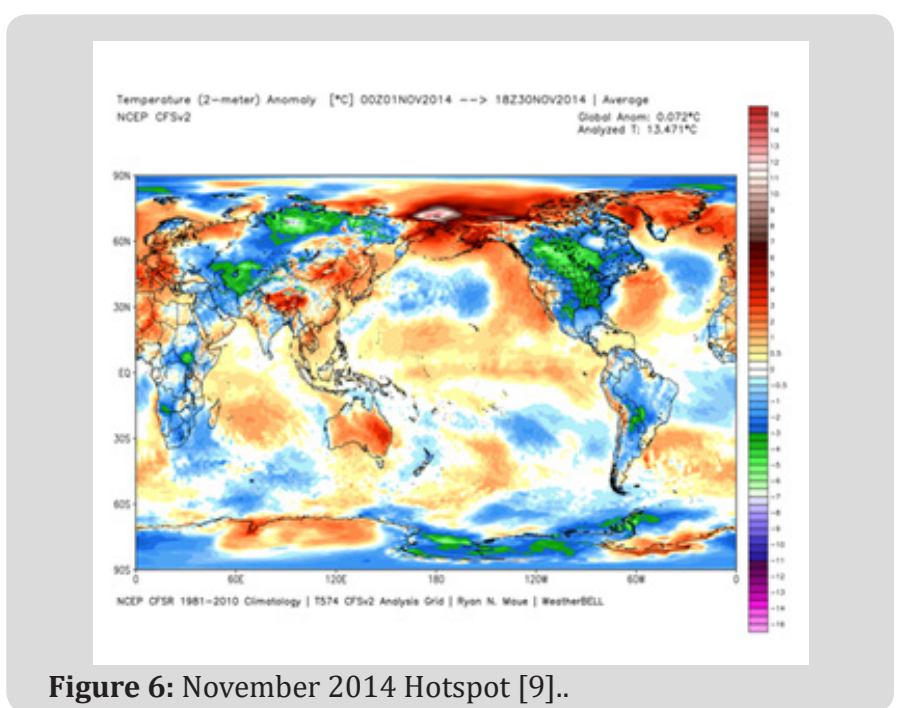

\section{Bombogenesis Storm from Tropical Storm Philippe October 2017}

Tropical storm Philippe is moving up the eastern seaboard of the USA and provides the Jekyll to the Hyde of a northeast USA bombogenesis [10,11]. (Table 1) provides the data for the V606 Aquilae debris stream traveling west of DA CAM date October 22 and theoretical longitude 53W to $60 \mathrm{~W}$ on October 29 . The magnetic correction of 10 degrees west is smaller because the storm is located in the St. Lawrence Valley (71W) on the northern border of the USA near the latitude where the longitude equation was correlated with the data, but $70 \mathrm{~W}$ is the predicted real longitude for the debris stream where the bombogenesis occurs. This storm is called bombogenesis because it intensifies over land.

\section{Bombogenesis Storm Hurricane Charley 2004}

(Figures 7 \& 8) emphasize the fact that Hurricane Charley 2004 is simply a storm that intensifies over Cuba which is not allowed by the old model [14]. It can be seen in (Figure 8) where the red of the positive magnetic anomaly on Cuba that Hurricane Charley's path encounters first is on land, so the new model is simply obeying the laws of physics and intensifies as the magnet strength of the storm increases. The white path is Hurricane Dennis July 8 to 10, 2005 
going north over a negative blue magnetic anomaly and decreasing in magnetic strength and velocity.

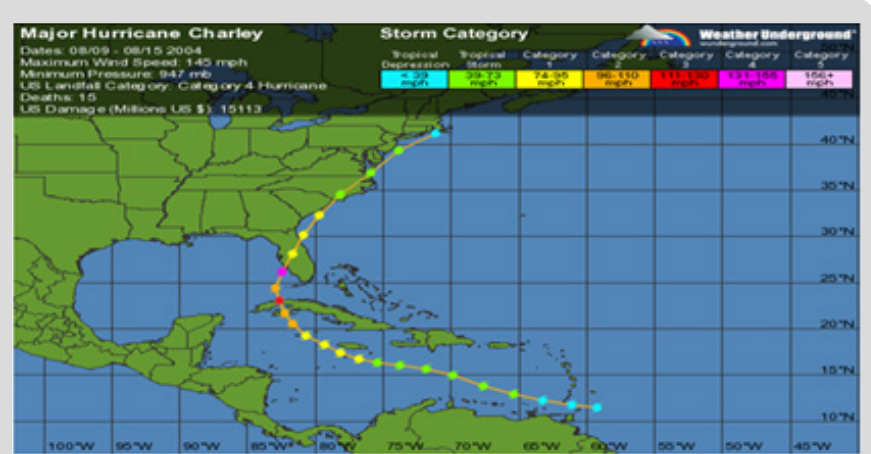

Figure 7: Bombogenesis Hurricane Charley [15].

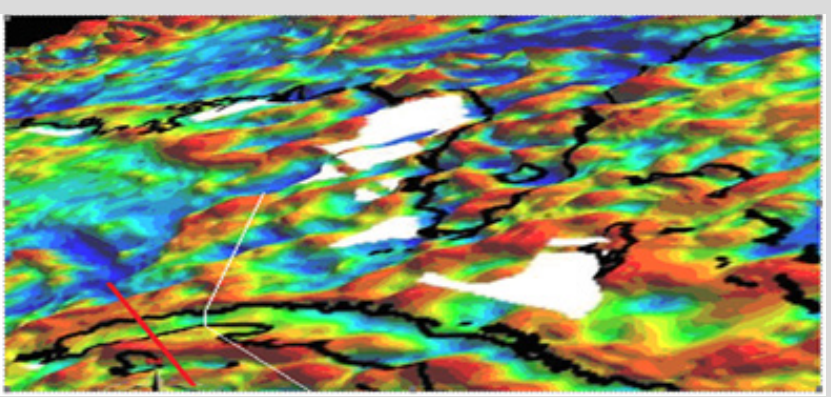

Figure 8: Magnetic Anomalies near Cuba [16] (WMAMH, 2011).

\section{Test the New Theory of Magnetic Hurricanes - Ship Graveyards - Real Proof}

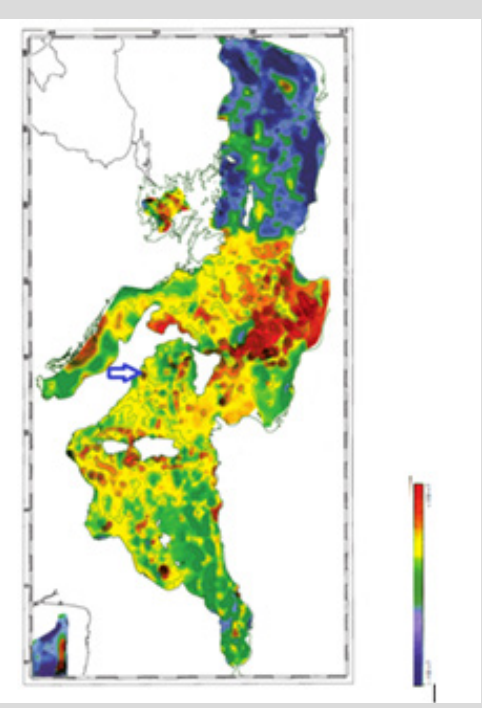

Figure 9: Magnetic Anomaly Map Mediterranean Sea [17].

Ventotene was an island shelter during Roman times from strong weather in the Mediterranean Sea shown by the location of the blue arrow in (Figure 9). The red dot in (Figure 9) also shows the location of a positive magnetic anomaly near or coincident with the island's location. Archeologists have discovered five Roman ships that sank in a period from the first century BC to the fifth century
$\mathrm{AD}$ at this location. Over the years, the severe storms that occurred due to the positive magnetic anomaly produce a graveyard of ships [18]. The depth of the Roman ships was a shallow 100 meters and caused the force that increases the velocity and magnetic strength of the storms to increase as the square of the distance between the magnetic poles is minimized. The author has not found the magnetic anomaly map that includes the Fournoi Korseon Island in the east Aegean Sea where 50+ ancient Greek ships have formed a graveyard of ships, but people are still dying in the treacherous waters of the east Aegean Sea [19,20].While searching for a lost plane in a zone 34.7S 92.6E and 35.3S 91.8E, a ship graveyard containing four ships was revealed [21,22]. One of the ships, the SV Inca, was a thousandyear-old Peruvian vessel that sank on it route from Peru to Sydney, Australia. The magnetic anomaly that caused the increase in storms velocity that sank these ships is noted by the red arrow in (Figure 10). These graveyards of ships provide proof for the new magnetic model of a tropical cyclone because the ships in ancient times were not constructed to survive an intense tropical cyclone.

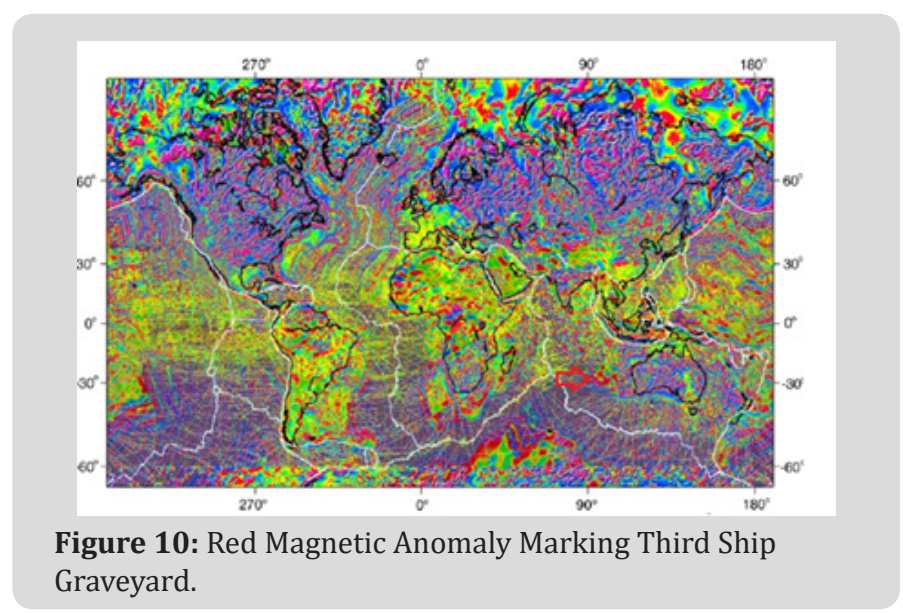

\section{Conclusion}

It is correct to say bombogenesis storms can be caused by incoming exploding star debris streams, but it is not correct to say all bombogenesis storms are caused by incoming debris streams because RI can be caused by other incoming solar storms by augmentation and strong magnetic anomalies. Changes in Earth's biosphere via unusual deaths and rapid intensification of cyclones are results of incoming debris streams from outer space's exploding stars known as nova and supernova. Until weathermen change the prevailing theories to recognize the truth, mankind will not design a system to protect the planet from incoming death of year 2083.The current model for cyclones, hurricanes, and typhoons all assume heat is absorbed from warm waters to power the storms. This incorrect assumption is clearly shown by the two storms of Typhoon Nuri and the bombogenesis of the Bering Sea of November 2014. These two storms are the same storm traveling under different names and neither is using heat energy from the ocean. Changes in our current system should be made to protect ships from out of season, cloudless hurricanes [23]. The other important change should prevent drilling for offshore oil near 
a region of positive magnetic anomalies see (Figure 8) that in combination with hurricane Ivan produced a fifteen-year oil spill in the Gulf of Mexico [24]. The accumulation of ships into graveyards that coincide with positive magnetic anomalies are solid proof that the suggested tropical storm model of positive ions revolving in a magnetic field is the correct model for the violent storms that sank those ships. If the correct model of a cyclone did not contain a magnetic field, graveyards of ships would not exist. The sooner weathermen develop theories with the new magnetic model; the sooner progress will be made particularly concerning RI.

\section{Addendum}

Please send financial support for this research in USA dollars to the Good Shepherd United Methodist Church, 210 W. Harrison Street, PO Box 336, Oakland City, IN 47660.

\section{References}

1. https://www.wunderground.com/hurricane/wp2014.asp

2. https://en.wikipedia.org/wiki/November_2014_Bering_Sea_cyclone

3. https://www.reference.com/science/magnets-repel-other$1 \mathrm{f} 8060 \mathrm{c} 6 \mathrm{fd} 3 \mathrm{aa} 38 \mathrm{e}$

4. Alan K Cooper (1977) The Bering Sea - A Multifarious Marginal Basin.

5. Sokeland wp (2017) Supernova and Nova Explosion's Space Weather: Correlated Megafauna Extinctions and Biosphere Meg-disturbancesGlobal Warming Journal of Earth Science and Engineering pp. 136-153.

6. Richard A Kock (2018) Saigas on the brink: Multidisciplinary analysis of the factors influencing mass mortality events 4(1).

7. https://en.wikipedia.org/wiki/V603_Aquilae
8. Jeff Halverson (2015) Bering Sea bomb cyclone ties record for strongest winter storm in North Pacific.

9. http://models.weatherbell.com/climate/cfsr_monthly.php

10. (2017) Northeast Storm Undergoes Bombogenesis, Bringing 70+ MPH Gusts, Almost 350 Reports of Wind Damage, Flooding.

11. https://www.wunderground.com/hurricane/atlantic/2017/ Remnants-of-Philippe

12. WMAMH (2011) Magnetic Anomalies near Hispaniola.

13. https://www.wunderground.com/hurricane/atlantic/2004/MajorHurricane-Charley

14. https://news.yahoo.com/bombogenesis-171923887.html

15. https://www.wunderground.com/hurricane/atlantic/2004/MajorHurricane-Charley

16. http://geomag.org/models/wdmam.html

17. http://www3.ogs.trieste.it/bgta/pdf/bgta39.1_ZANOLLA.pdf

18. (2009) Archaeologists find graveyard of sunken Roman ships

19. (2016) 23 Wrecks Found in Ship Graveyard in Aegean Sea in Just 22 Days.

20. https://www.dw.com/en/treacherous-aegean-sea-claims-moremigrant-lives/a-18817930

21. Stewart Perrie (2018) MH370 Investigators Find Mysterious Ship Graveyard in Search Area.

22. Steve Creedy and Geoffrey Thomas (2018) MH370 crash site could be known within a week.

23. Adam Warner (2018) Cruise Ship That Was Rocked by Storm to Return to New Jersey.

24. https://en.wikipedia.org/wiki/Taylor_oil_spill.

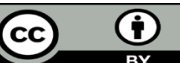

This work is licensed under Creative Commons Attribution 4.0 License

To Submit Your Article Click Here:

Submit Article

DOI: $10.32474 /$ RRHOAJ.2019.04.000178

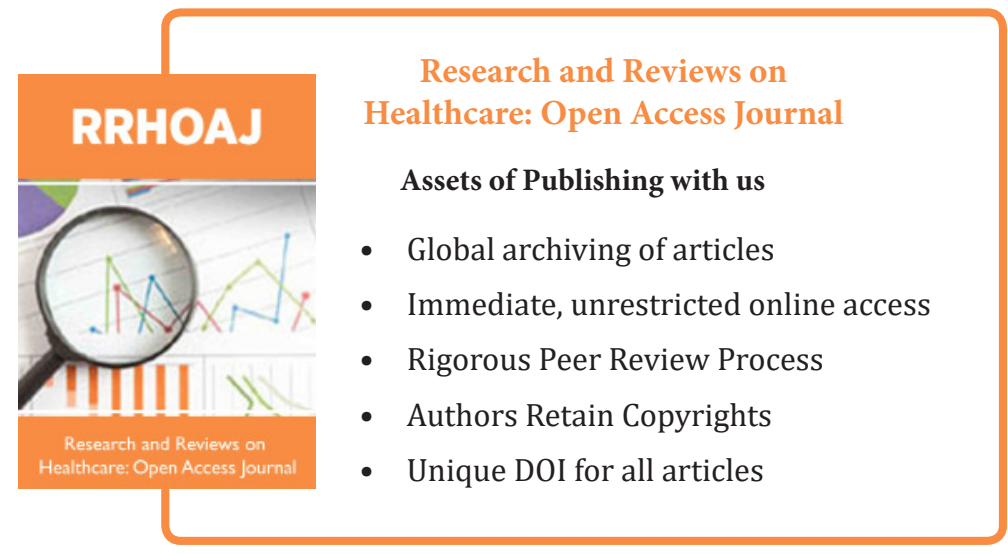

